\title{
LA SENTENCIA DE LA CIDH EN EL CASO LHAKA HONHAT (NUESTRA TIERRA) VS. ARGENTINA: LOS DESCA EN EL MARCO DE LOS CONFLICTOS ETNOAMBIENTALES
}

\section{THE JUDGMENT OF THE IACHR IN THE CASE OF LHAKA HONHAT (OUR LAND) VS. ARGENTINA: ESCER WITHIN THE FRAMEWORK OF ETHNO-ENVIRONMENTAL CONFLICTS}

\section{María Laura Foradori}

DOI: https://doi.org/10.37767/2591-3476(2021)07

\section{Comentario a}

Caso Comunidades Indígenas Miembros de la Asociación Lhaka Honhat (Nuestra Tierra) vs. Argentina - Sentenia de 6 de febrero de 2020

Corte Interamericana de Derechos Humanos

Disponible en

https://bit.ly/3Bi2VtX

\section{RESUMEN:}

Este trabajo tiene como propósito destacar los principales argumentos de la Corte Interamericana de Derechos Humanos en la sentencia del caso "Comunidades Indígenas miembros de la Asociación Lhaka Honhat (Nuestra Tierra) vs. Argentina", de febrero del año 2020, donde declara la responsabilidad internacional del Estado Argentino por la violación de distintos derechos de 132 comunidades indígenas. La sentencia es un precedente clave para la justiciabilidad y exigibilidad de los DESCA, destacando la importancia fundamental de la propiedad comunitaria indígena (artículo $21 \mathrm{CADH}$ ) para el goce efectivo de los demás derechos analizados (DESCA del artículo 26 CADH): a un ambiente sano, a la alimentación adecuada, al agua y a la identidad cultural; estableciendo su interdependencia y autonomía. Se hará este repaso siguiendo los apartados de la sentencia, y comprendiendo los DESCA en el marco de los conflictos etnoambientales. 


\begin{abstract}
The purpose of this work is to highlight the main arguments of the Inter-American Court of Human Rights in the Judgment of the case "Indigenous Communities members of the Lhaka Honhat (Our Land) Association vs. Argentina", of February 2020, where it declares the international responsibility of the Argentine State for the violation of different rights of 132 indigenous communities. The Judgment is a key precedent for the justiciability and enforceability of the DESCA, highlighting the fundamental importance of indigenous community property (Article $21 \mathrm{ACHR}$ ) for the effective enjoyment of the other rights analyzed (DESCA of Article 26 ACHR): to a healthy environment, to adequate food, water and cultural identity; establishing their interdependence and autonomy. This review will be carried out following the sections of the Judgment, and understanding the ESCR in the framework of ethno-environmental conflicts.
\end{abstract}

PALABRAS CLAVE: Corte Interamericana de Derechos Humanos; Lhaka Honhat vs. Argentina; DESCA; conflictos etnoambientales; pueblos indígenas.

KEY WORDS: Inter-American Court of Human Rights; Lhaka Honhat vs. Argentina; DESCA; ethno-environmental conflicts; Indigenous villages.

\title{
I. Introducción
}

Los conflictos etnoambientales, aquellos que reúnen las problemáticas ambientales e indígenas, se han multiplicado en los últimos años, afectando de diversas maneras los Derechos Económicos, Sociales, Culturales y Ambientales (DESCA). Las particulares características de estos conflictos conllevan diferentes desafíos para los Estados, tanto respecto a las políticas públicas como a la resolución de los procesos judiciales vinculados con esta problemática. En Argentina, uno de los principales obstáculos para el respeto de los DESCA de las comunidades indígenas es la falta de una reglamentación adecuada de los derechos reconocidos en el artículo 75 inciso 17 de nuestra Constitución Nacional. Para contrarrestar esas deficiencias, ha sido y es de fundamental importancia "la consideración de estos derechos como operativos por la jurisprudencia y la adopción de los estándares internacionales en la materia a la hora de su interpretación y aplicación" (Chiacchiera Castro, 2019: 2).

En ese marco general, aquí se comenta la sentencia de la Corte Interamericana de Derechos Humanos (en adelante Corte, Tribunal o $\mathrm{CIDH}$ ) en el caso "Comunidades Indígenas miembros de la Asociación Lhaka Honhat (Nuestra Tierra) vs. Argentina", del 6 de febrero de 2020, que viene a echar luz sobre la cuestión al analizar de manera holística diferentes DESCA con la especificidad de los pueblos indígenas. En el fallo, la Corte declaró la responsabilidad de la República Argentina por la violación de distintos derechos de 132 comunidades indígenas que habitan en la Provincia de Salta. El Tribunal determinó que el Estado violó los derechos a la propiedad comunitaria y a la identidad cultural, a un medio ambiente sano, a la alimentación adecuada y al agua, por la falta de efectividad de medidas estatales para detener actividades que resultaron lesivas a estos derechos.

El caso es de suma importancia porque es la primera vez que la Corte se pronuncia en 
un caso contencioso sobre los derechos a un medio ambiente sano, a la alimentación adecuada, al agua y a la identidad cultural en forma autónoma a partir del artículo 26 de la Convención Americana de Derechos Humanos (en adelante CADH o Convención). Estos DESCA no sólo son examinados en su interdependencia, sino también, respecto a los pueblos indígenas específicamente. Además de ello, la sentencia es un antecedente clave para los derechos humanos porque ordena diferentes medidas de reparación específicas al Estado en cuanto a sus marcos normativos y políticas públicas.

Recordemos que la CIDH es un tribunal regional que tiene por objetivo aplicar e interpretar la CADH, también llamada Pacto de San José de Costa Rica, que ha sido ratificada por Argentina y tiene jerarquía constitucional conforme al artículo 75 inciso 22 de la Constitución Nacional (reforma de 1994). La Corte tiene tres tipos de funciones: consultiva, la de dictar medidas provisionales y contenciosa, competencia que ha reconocido Argentina.

Se trata de un fallo extenso, de más de 100 páginas, que no ha sido sencillo reducir para presentarlo en este comentario, ya que se expresan consideraciones de la Corte de fundamental importancia. Por ello, en lo que sigue, y teniendo en cuenta la extensión permitida, se hará un repaso del caso, con los hechos y el proceso que ha seguido; para luego detenernos en los argumentos brindados por la Corte al considerar el fondo de la cuestión a decidir, en particular se hará hincapié en el derecho de propiedad comunitaria indígena, el derecho a la información, la participación y acceso a la justicia; y los derechos a un medio ambiente sano, a la alimentación adecuada, al agua y a participar en la vida cultural, destacando su interpretación no restrictiva e interrelación. En el desarrollo de esta reconstrucción de las partes principales del fallo se hará especial referencia a los conflictos etnoambientales, sus características, sus causas y la vinculación con los DESCA.

\section{El caso: un recuento de los hechos y el proceso}

El eje del litigio es un reclamo de propiedad de comunidades indígenas sobre tierras ubicadas en la Provincia de Salta - Argentina, en la región del Chaco Salteño (en el límite con Paraguay y Bolivia). Se trata de múltiples comunidades de diferentes pueblos indígenas que habitan una extensión de tierra (ex lotes fiscales 14 y 55) de 643 mil hectáreas aproximadamente. Se estima que en la zona ha habido presencia de comunidades indígenas de modo constante, al menos desde antes de 1629; y además hay personas criollas en esas tierras a partir de inicios del siglo XX.

Este reclamo lleva cerca de 35 años, período en el cual el Estado adoptó diferentes normas y acciones; entre los cuales la CIDH destaca que algunas de ellas, llevadas a cabo en los años 1991, 2012 y 2014, avanzaron en el reconocimiento de la propiedad indígena. A pesar de esos avances, la implementación de diferentes acciones en el territorio indígena no ha cesado. Entre ellas se destaca la presencia de población no indígena en la tierra reclamada, población criolla, que lleva a cabo diversas actividades: cría de ganado, alambrados y tala ilegal. También, sobre dichas tierras se realizan otros proyectos y obras, como ser la construcción de un puente internacional, dos rutas (una nacional y otra provincial), y la exploración de hidrocarburos.

Luego de diferentes acciones administrativas y judiciales en Argentina, el 4 de agosto de 1998 la Comisión Interamericana de Derechos Humanos (en adelante Comisión) recibió la petición inicial presentada por Lhaka Honhat, con el patrocinio del Centro de Estudios Legales y Sociales (CELS) y el Centro por la Justicia y el Derecho Internacional (CEJIL). En el 
año 2006 aprobó el Informe de Admisibilidad N78/06; y en el año 2012 aprobó el Informe de Fondo $\mathrm{N}^{\circ} 2 / 12$, con conclusiones y recomendaciones para Argentina. La Comisión concluyó que Argentina violó el derecho a la propiedad de las comunidades indígenas que forman parte de la Asociación Lhaka Honhat porque a pesar de las solicitudes presentadas por las comunidades, el Estado no sólo que nunca proveyó acceso efectivo al título de propiedad sobre su territorio ancestral; sino que además omitió emprender acciones efectivas para el control de las intromisiones en ese territorio indígena, como la deforestación, el llevar a cabo obras públicas y otorgar concesiones para la exploración de hidrocarburos sin las consultas previas, libres e informadas, ni los estudios de impacto social y ambiental previos. Además, dictaminó que violó la libertad de pensamiento y expresión y los derechos políticos, de acceso a la información y a participar en los asuntos susceptibles de afectarles. Sostuvo, también, que violó los derechos a las garantías judiciales y a la protección judicial "debido a la falta de provisión de un procedimiento efectivo para acceder a la propiedad del territorio ancestral; así como a las variaciones sucesivas en el procedimiento administrativo aplicable a la reclamación territorial indígena".

Luego de varias prórrogas otorgadas a Argentina para el cumplimiento de las recomendaciones; en febrero de 2018 la Comisión sometió el caso a la CIDH y le solicitó que concluya y declare la responsabilidad internacional de Argentina por las violaciones establecidas en el Informe de Fondo, y que también ordene medidas de reparación.

Ya en la Corte, en mayo de 2018, el CELS y Lhaka Honhat, presentaron el escrito de solicitudes, argumentos y pruebas, donde coincidieron con las conclusiones de la Comisión, y además, alegaron la violación al derecho al reconocimiento de la personalidad jurídica, a la libertad de asociación, a la libertad de circulación y de residencia y a los derechos a la identidad cultural, a la alimentación adecuada y a un medio ambiente sano, que adujeron contenidos en el artículo 26 de la Convención. En el mes de septiembre del mismo año, se presentó el escrito de contestación por parte del Estado argentino, donde opuso un argumento que denominó "excepción preliminar", negando las violaciones alegadas y respondiendo a las solicitudes de reparación. Luego se llevó a cabo una audiencia pública en la sede de la Corte, el Tribunal recibió escritos de Amicus Curiae, también se realizó en el año 2019 una "visita a terreno" o diligencia in situ.

En definitiva, la Corte concluyó que Argentina violó las siguientes disposiciones de la CADH: 1) el artículo 21, que reconoce el derecho de propiedad, en relación con los derechos a las garantías judiciales y a la protección judicial, receptados en los artículos 8.1 y 25.1 y la obligación de adoptar disposiciones de derecho interno mandada en el artículo 2; 2) el artículo 23.1, que reconoce el derecho a la participación; 3) el artículo 26, que recoge los DESCA; y 4) el artículo 8.1, por la demora en la resolución de una causa judicial.

A partir de lo anterior, el Tribunal ordenó al Estado, como medidas de reparación, que con la mayor celeridad posible y en un plazo máximo de seis años: a) Concluya las acciones necesarias a fin de delimitar, demarcar y otorgar un título que reconozca la propiedad de las 132 comunidades indígenas sobre su territorio; b) Remueva del territorio indígena los alambrados y el ganado de pobladores criollos y concrete el traslado de la población criolla fuera de ese territorio.

Además de esas medidas específicas para el caso; la Corte dispuso que su sentencia constituye por sí misa una forma de reparación general, sentando un gran precedente 
al ordenar a Argentina las siguientes cuestiones: “i) abstenerse de realizar actos, obras o emprendimientos sobre el territorio indígena o que puedan afectar su existencia, valor, uso o goce, sin la previa provisión de información a las comunidades indígenas víctimas, así como de la realización de consultas previas adecuadas, libres e informadas, de acuerdo a pautas señaladas en la Sentencia; ii) presentar a la Corte un estudio que identifique situaciones críticas de falta de acceso a agua potable o alimentación, formule un plan de acción para atender esas situaciones y comience su implementación; iii) elaborar, en un plazo máximo de un año, un estudio en el que establezca acciones que deben instrumentarse para la conservación de aguas y para evitar y remediar su contaminación; garantizar el acceso permanente a agua potable; evitar que continúe la pérdida o disminución de recursos forestales y procurar su recuperación, y posibilitar el acceso a alimentación nutricional y culturalmente adecuada; iv) crear un fondo de desarrollo comunitario e implementar su ejecución en un plazo no mayor a cuatro años; v) realizar, en un plazo máximo de seis meses, publicaciones de la Sentencia y su resumen oficial, así como actos de difusión de este último documento, inclusive por emisiones de radio, en lenguas indígenas y en español; vi) adoptar, en un plazo razonable, las medidas legislativas y/o de otro carácter que fueren necesarias para dotar de seguridad jurídica al derecho de propiedad comunitaria indígena, previendo procedimientos específicos para tal fin; vii) pagar, en el plazo de seis meses, una suma de dinero, fijada en la Sentencia, por concepto de reintegro de gastos y costas; viii) rendir al Tribunal informes semestrales sobre las medidas de restitución del derecho de propiedad, y ix) informar a la Corte en el plazo de un año sobre las medidas adoptadas para cumplir con todas las medidas ordenadas en la misma." ${ }^{\prime 2}$

El cumplimiento íntegro de la sentencia será supervisado por la Corte, conforme a los deberes que surgen de la Convención; y dará por concluido el caso una vez que el Estado haya dado cabal cumplimiento a las medidas reparatorias ordenadas.

\section{Los argumentos de la Corte: el marco normativo y conceptual de los derechos implicados}

A partir de lo anterior, en este apartado, se reconstruyen los argumentos brindados por el Tribunal respecto a los derechos vulnerados, haciendo especial referencia al derecho de propiedad comunitaria indígena, que se considera la base de los demás, al derecho a la información, la participación y el acceso a la justicia, y a los derechos a un medio ambiente sano, a la alimentación adecuada, al agua y a la cultura (DESCA).

Una de las primeras cuestiones que define la $\mathrm{CIDH}$ es que se trata de un caso colectivo, identificando como presuntas víctimas a las 132 comunidades indígenas indicadas por los representantes (CELS y Lhaka Honhat). También deja sentado que los lotes 14 y 55 están habitados también por "criollos", pobladores no indígenas, que no son parte formal del proceso judicial internacional; pero si lo son en un sentido material, por cuanto son parte del conflicto sustantivo relacionado con el uso y propiedad de la tierra. Por ello, tendrá en cuenta su situación en tanto resulta pertinente a efectos de analizar adecuadamente el caso planteado y procurar la efectividad de la decisión que se adopta en la sentencia.

Para organizar este extenso apartado, se seguirá el orden presentado por la Corte en la sentencia, y se irán exponiendo sus argumentos de la mano con el marco normativo de

2 Resumen Oficial de la Sentencia emitido por la Corte Interamericana. Pp. 5-6. Disponible en: https://www.corteidh.or.cr/docs/casos/articulos/resumen_400_ esp.pdf 
los derechos en cuestión, además de consideraciones doctrinarias y conceptuales. Por ello, en primer lugar nos referiremos al derecho de propiedad comunitaria indígena y luego haremos hincapié en el análisis e interdependencia de los derechos a un medio ambiente sano, a la alimentación adecuada, al agua y a la identidad cultural; para finalizar, en el próximo apartado, con el análisis de los DESCA en el marco de los conflictos etnoambientales.

\section{IV.1. El derecho de propiedad comunitaria indígena}

Lillo Vera (2017) plantea que se debe comprender al territorio como un derecho colectivo de los pueblos indígenas, distinguiéndolo así del derecho a la tierra, que es un derecho individual. En este sentido, el concepto de territorio implica un espacio donde los indígenas ejercen su influencia y autodeterminación, incorporando de esta manera los elementos que conforman el hábitat indígena (suelo, subsuelo, agua, bosque, animales, etc).

El derecho al territorio, es la base de los DESCA; su vulneración afecta al resto de los derechos que se desarrollan a continuación. La protección de la relación especial de los pueblos indígenas con sus territorios, garantiza su propia subsistencia al permitir vivir en un ambiente sano, acceder al agua potable y a los alimentos adecuados. La Corte se ha referido en varias oportunidades al derecho de propiedad comunitaria indígena, y en esta sentencia cita varios precedentes.

En el caso de la "Comunidad Mayagna (Sumo) Awas Tingni Vs. Nicaragua" la Corte estableció que el derecho a la propiedad privada plasmado en el artículo 21 de la CADH comprende, en relación con los pueblos indígenas, la propiedad comunal de sus tierras. En ese caso, explicó que:

“entre las personas indígenas existe una tradición comunitaria sobre una forma comunal de la propiedad colectiva de la tierra, en el sentido de que la pertenencia de ésta no se centra en un individuo sino en el grupo y su comunidad. Los indígenas por el hecho de su propia existencia tienen derecho a vivir libremente en sus propios territorios; la estrecha relación que los indígenas mantienen con la tierra debe de ser reconocida y comprendida como la base fundamental de sus culturas, su vida espiritual, su integridad y su supervivencia económica"3.

Avanzando un poco más en este derecho a la propiedad de la tierra, en el caso "Comunidad Indígena Yakye Axa Vs. Paraguay" del año 2005, la Corte amplió lo que entiende por el derecho a la propiedad, al no sólo referirse a sus territorios, sino también a los recursos naturales ligados a su cultura que allí se encuentren y los elementos que se desprendan de ellos. En la sentencia del caso "Pueblo Saramaka Vs. Surinam", explicó que "el derecho a usar y gozar del territorio carecería de sentido si no estuviera conectado con los recursos naturales que se encuentran dentro del territorio". Por ello, la titularidad de la tierra está unida a la "necesidad de garantizar la seguridad y la permanencia del control y uso de los recursos naturales [...], lo que a su vez, mantiene el estilo de vida" de las comunidades. Los recursos que están protegidos por el derecho de propiedad comunitaria son los que las comunidades "han usado tradicionalmente y que son necesarios para la propia supervivencia, desarrollo y continuidad de su estilo de vida". Por eso, la realización, por el Estado o terceros, de actividades que puedan "afectar la integridad de las tierras y recursos naturales" deben seguir ciertas pautas que el Estado debe garan-

3 Caso de la Comunidad Mayagna (Sumo) Awas Tingni Vs. Nicaragua. Pp. 36 de la sentencia analizada 
tizar: la participación efectiva de las comunidades afectadas; su beneficio en términos razonables y la previa realización de estudios de impactos sociales y ambientales ${ }^{4}$.

Luego de expresar la importancia y el significado del derecho al territorio para las comunidades originarias, la Corte cita nuevamente su decisión en el caso "Yake Axa Vs. Paraguay" para dejar claro que la obligación del Estado no se satisface sólo con reconocer el derecho de propiedad comunitaria, sino que debe hacerlo efectivo en la realidad. Conforme a la Corte, para que el Estado asegure la propiedad efectiva de los pueblos indígenas, debe: "a.- deslindar las tierras indígenas de otras y otorgar título colectivo de las tierras a las comunidades; b.-abstenerse de realizar actos que puedan llevar a que los agentes del propio Estado, o terceros que actúen con su aquiescencia o su tolerancia, afecten la existencia, el valor, el uso o el goce de su territorio, y c.- a su vez, garantizar el derecho de los pueblos indígenas de controlar y usar efectivamente su territorio y recursos naturales, así como de ser propietarios de su territorio sin ningún tipo de interferencia externa de terceros" ${ }^{\prime \prime}$.

En base a dichos precedentes, y después de considerar los argumentos presentados por la Comisión y las partes respecto al reconocimiento y la determinación de la propiedad, la Corte expone que no está en discusión el derecho de propiedad de las comunidades indígenas sobre su territorio ancestral, y que ha sido reconocido en diferentes actos estatales. Lo que si debe analizar y determinar es si el Estado ha brindado seguridad jurídica adecuada al derecho de propiedad comunitaria, permitiendo el libre ejercicio y goce de ese derecho, a través de la adopción de las medidas legislativas y administrativas necesarias.

A partir de lo anterior, expresa que si bien han existido distintos actos estatales relacionados con el reconocimiento de la propiedad, ellos no han sido el resultado del desarrollo de un procedimiento reglado, establecido en forma legal y previa; y advierte sobre la complejidad y dificultades del caso para garantizar el derecho de propiedad cuando también habitan personas criollas las mismas tierras. Por lo que concluye que el derecho de propiedad de las comunidades indígenas sobre su territorio no se encuentra satisfecho.

El marco normativo que en Argentina existe y que se presenta insuficiente para garantizar el derecho a la propiedad indígena está conformado en primer lugar por la Constitución Nacional, que con la reforma de 1994 dotó de jerarquía constitucional a instrumentos internacionales de derechos humanos, entre ellos la $\mathrm{CADH}$, e incorporó el artículo 75 inciso 17, donde entre las atribuciones del Congreso establece: "Reconocer la preexistencia étnica y cultural de los pueblos indígenas argentinos. Garantizar el respeto a su identidad y el derecho a una educación bilingüe e intercultural; reconocer la personería jurídica de sus comunidades, y la posesión y propiedad comunitarias de las tierras que tradicionalmente ocupan; y regular la entrega de otras aptas y suficientes para el desarrollo humano; ninguna de ellas será enajenable, transmisible ni susceptible de gravámenes o embargos. Asegurar su participación en la gestión referida a sus recursos naturales y a los demás intereses que los afecten. Las provincias pueden ejercer concurrentemente estas atribuciones."

Se trata de una cláusula fundamental, que atraviesa a todos los derechos desarrollados en la sentencia, pero se critica la falta de operatividad de la misma y su inclusión entre

4 Caso del Pueblo Saramaka Vs. Surinam. Pp. 37 de la sentencia analizada

5 Caso Yake Axa Vs. Paraguay. Pp. 39 de la sentencia analizada. 
las facultades del Congreso Nacional, en lugar de hacerlo entre los Principios, Derechos y Garantías (Moreira, 2011).

Otras leyes que hacen referencia a la cuestión del territorio indígena son: la Ley N²3.302 (1985) sobre Política Indígena y apoyo a las Comunidades Aborígenes; la Ley N²4.071 (1992) que aprobó el Convenio N¹69 de la Organización Internacional del Trabajo (OIT) sobre pueblos indígenas y tribales en países independientes; la Ley Nº 26.160 (2006) de Relevamiento Territorial de Comunidades Indígenas, que fue promulgada para dar respuesta a la situación de emergencia en materia de posesión y propiedad de las tierras que ocupan las comunidades indígenas en Argentina, con el fin de lograr la regularización dominial. Aquí también se destaca el Código Civil y Comercial, Ley N²6.994, que en el artículo 18 establece: "Las comunidades indígenas reconocidas tienen derecho a la posesión y propiedad comunitaria de las tierras que tradicionalmente ocupan y de aquellas otras aptas y suficientes para el desarrollo humano según lo establezca la ley, de conformidad con lo dispuesto por el artículo 75 inciso 17 de la Constitución Nacional."

Como resultado del análisis efectuado, la Corte entiende que no se ha tutelado de manera efectiva el derecho a la propiedad de las comunidades indígenas; quedando sujetas a diferentes negociaciones y decisiones gubernamentales sobre su propiedad, que, en la práctica no han concretado adecuadamente su derecho. En otras palabras, no hay seguridad jurídica respecto a la propiedad del territorio, ya que Argentina no cuenta con normativa adecuada para garantizar el derecho, además no se ha demarcado y subsiste la permanencia de terceros.

\section{IV.2. Los derechos de acceso a la información y la participación de las comunidades originarias}

Como parte del derecho a la propiedad comunitaria, tanto la Comisión como los representantes, sostuvieron que el Estado vulneró los derechos de acceso a la información y a la participación de las comunidades originarias respecto a la realización de obras públicas (puente internacional y rutas) y otorgamiento de concesiones de hidrocarburos en territorio ancestral; incumpliendo con el estudio de impacto ambiental y social que debe garantizarse de forma previa a las actividades señaladas.

La Corte ha indicado que los pueblos indígenas deben ser consultados de forma adecuada en cuestiones atinentes a sus tierras y decisiones que afecten sus derechos. De acuerdo con lo señalado por el Tribunal, respecto a obras o actividades dentro del territorio indígena, el Estado, debe cumplir con tres garantías: 1) "asegurar la participación efectiva de los pueblos o comunidades, de conformidad con sus costumbres y tradiciones, deber que requiere que el Estado acepte y brinde información, y que implica una comunicación constante entre las partes. Las consultas deben realizarse de buena fe, a través de procedimientos culturalmente adecuados y deben tener como fin llegar a un acuerdo." 2) "garantizar que no se emitirá ninguna concesión dentro del territorio a menos y hasta que entidades independientes y técnicamente capaces, bajo la supervisión del Estado, realicen un estudio previo de impacto [...] ambiental." 3) "garantizar que las comunidades indígenas se beneficien razonablemente del plan que se lleve a cabo dentro de su territorio."

En base al análisis que expone, la Corte concluye que Argentina no cumplió su obligación de procurar mecanismos adecuados de consulta libre, previa e informada a las comuni- 
dades indígenas afectadas; vulnerando así su derecho de propiedad y a la participación, pero no se pronuncia sobre la posible lesión al derecho a acceder a la información. Si bien en la sentencia se analiza como un tercer eje respecto al fondo: las garantías judiciales y el acceso a la justicia, consideramos que es posible hacer referencia aquí, porque se encuentra íntimamente vinculado con los derechos anteriores.

Respecto a estos derechos de acceso, es fundamental destacar la reciente entrada en vigencia (22/4/2021) del Acuerdo Regional sobre el Acceso a la Información, la Participación Pública y el Acceso a la Justicia en Asuntos Ambientales en América Latina y el Caribe ${ }^{6}$, conocido como Acuerdo de Escazú. Fue ratificado por Argentina a través de la Ley $N^{\circ} 27566$, y viene a fortalecer los llamados derechos de acceso en cuestiones ambientales: a la información, a la participación y a la justicia. Constituye el primer Tratado de Derechos Humanos de América Latina y el Caribe en materia de protección ambiental, y hace especial énfasis en garantizar la protección de los defensores de derechos humanos en asuntos ambientales y en la igualdad para el acceso a los derechos mencionados.

En el marco de los conflictos etnoambientales, el Acuerdo de Escazú se presenta como un instrumento de fundamental importancia para la defensa del territorio por parte de los pueblos indígenas, ya que en sus batallas son asediados por los grandes poderes e intereses de quienes promueven las actividades extractivas, luchando en condiciones desfavorables. Esto provoca que sus "líderes y lideresas, así como numerosos aliados en estas luchas, sufran agresiones y amenazas que pueden llegar a graves daños físicos o incluso la muerte" (Hualpa, 2020: 17).

Para garantizar esa igualdad de condiciones en el acceso a la información, el artículo 5, hace especial hincapié en las personas o grupos en situación de vulnerabilidad, y los pueblos indígenas y grupos étnicos; estableciendo que los Estados deben facilitar el acceso considerando sus condiciones y especificidades, garantizando que reciban asistencia para formular sus peticiones y obtener respuesta. Respecto a la participación pública en los procesos de toma de decisiones ambientales, el artículo 7 establece que los Estados Parte del Acuerdo deben garantizar en su implementación el respeto de su legislación nacional y de sus obligaciones internacionales relativas a los derechos de los pueblos indígenas y comunidades locales.

El derecho a la consulta previa indígena tiene ciertas características determinadas por instrumentos internacionales ${ }^{7}$. Entre esos elementos esenciales se destacan: carácter previo, buena fe y finalidad de llegar a un acuerdo, procedimiento culturalmente adecuado y accesible, informada previamente, y el consentimiento debe ser libre, previo e informado8.

Como se expresó en la introducción, estos conflictos etnoambientales presentan un gran desafío para el acceso a la justicia, que no está libre de diversos obstáculos, constituyendo uno de ellos la adecuación cultural del proceso, exigencia derivada también del artículo 75 inciso 17 y del artículo 12 del Convenio №169 de la OIT, que específicamente expresa: “Los pueblos interesados deberán tener protección contra la violación de sus

\footnotetext{
6 Este Acuerdo viene a desarrollar y hacer efectivo el Principio 10 de la Declaración de Rio 92

7 El marco normativo del consentimiento libre, previo e informado está dado por una serie de instrumentos legales internacionales, entre los se encuentran la Declaración de las Naciones Unidas sobre Derechos de los Pueblos Indígenas, el Convenio 169 de la OIT y el Convenio sobre la Diversidad Biológica.

8 Amicus Curiae presentado ante la CIDH por la Fundación Ambiente y Recursos Naturales (FARN) en el año 2019.
} 
derechos, y poder iniciar procedimientos legales, sea personalmente o bien por conducto de sus organismos representativos, para asegurar el respeto efectivo de tales derechos. Deberán tomarse medidas para garantizar que los miembros de dichos pueblos puedan comprender y hacerse comprender en procedimientos legales, facilitándoles, si fuere necesario, intérpretes u otros medios eficaces." Esta adecuación cultural implica que por ejemplo la lengua no deba ser un obstáculo para el acceso, que adquieren particular relevancia las pericias antropológicas, que se requiere una especial formación de los operadores jurídicos, que debe haber intérpretes y traductores indígenas en estos procesos, entre otras cuestiones.

Respecto a lo anterior, el párrafo 4 del artículo 8 del Acuerdo de Escazú, establece que para facilitar el acceso a la justicia en asuntos ambientales, los Estados, entre otras cuestiones, establecerán, “[...] d) el uso de la interpretación o la traducción de idiomas distintos a los oficiales cuando sea necesario para el ejercicio de ese derecho."

\section{IV.3. Los derechos a un medio ambiente sano, a la alimentación adecuada, al agua y a participar en la vida cultural}

En el caso analizado, los representantes manifestaron que el Estado vulneró los derechos al medio ambiente sano, a la identidad cultural y a la alimentación adecuada, que consideraron contenidos en el artículo 26 de la CADH. Este menoscabo se produjo por la presencia de pobladores criollos que dañaron la integridad ambiental del territorio a través de la deforestación ilegal, la colocación de alambrados y el sobrepastoreo de ganado. Señalaron que la pérdida de flora impacta en el hábitat natural de fauna silvestre, la que además compite con el ganado para el consumo de alimento y agua. Agregaron que la pérdida de flora y fauna autóctonas se ha relacionado además con la instalación de alambrados en el territorio, que "constituyen obstáculos naturales" para el desarrollo de aquellas.

Además, indicaron que "cómo consecuencia de la degradación ambiental" y el "cercamiento" de los criollos, "se verifica una vulneración del derecho a la alimentación de las comunidades". Especificaron que el ganado de los pobladores criollos se alimenta de los mismos frutos que las comunidades indígenas, además impide la regeneración de algunos árboles, consume el agua que las propias comunidades requieren para su subsistencia, y muchas veces la contaminan con sus heces, entre otras situaciones que menoscaban el derecho.

Los representantes agregaron que "la presencia de cientos de familias criollas en el territorio ancestral, la degradación ambiental [...] y la alteración de los campos de caza y recolección de las comunidades [indígenas] han tenido un efecto profundo en su identidad cultural y prácticas tradicionales". Afirmaron que lo anterior ha provocado en las comunidades "profundas alteraciones" en "sus costumbres, sus hábitos sociales e individuales, sus prácticas económicas y sus concepciones acerca del mundo y de su propia vida". En ese sentido, observaron que dada la especial relación de las comunidades con su tierra, "la degradación del ambiente y los cambios en la flora y la fauna, exceden del aspecto meramente económico y de subsistencia, afectando la identidad [cultural]".

Si bien los representantes no han alegado la violación del derecho humano al agua, la Corte incorpora el mismo porque tiene competencia para analizar la posible violación de las normas de la Convención que no han sido incorporadas por las partes.

Este es el primer caso contencioso en el que la Corte debe pronunciarse respecto a los 
derechos a un medio ambiente sano, a la alimentación adecuada, al agua y a participar de la vida cultural a partir del artículo 26 de la Convención. Por ello, se detiene a analizar cada uno de estos derechos considerando especialmente sus particularidades respecto a los pueblos indígenas. A continuación seguiremos los apartados de análisis que realiza la Corte, para repasar los argumentos principales.

\section{IV.3.a. El derecho a un medio ambiente sano}

La Corte ya se ha manifestado respecto a este derecho en la Opinión Consultiva 23/17, y considera al derecho al medio ambiente sano como incluido en los derechos protegidos por el artículo 26 de la CADH. En la Opinión Consultiva expuso que se trata de un derecho fundamental para la existencia de la humanidad, y que no sólo es un derecho instrumental sino un derecho autónomo que protege al ambiente y sus componentes por su valor intrínseco, y no solamente por su importancia para los seres humanos (otros derechos humanos pueden ser vulnerados como consecuencia de daños al ambiente), sino para los demás organismos vivos con quienes se comparte el planeta.

La Corte destaca que como contrapartida del derecho al ambiente sano no sólo encontramos la obligación de respeto sino la de garantizar ese derecho y prevenir violaciones. En este sentido, "Ios Estados tienen la obligación de establecer mecanismos adecuados para supervisar y fiscalizar ciertas actividades, a efecto de garantizar los derechos humanos, protegiéndolos de las acciones de entidades públicas, así como de personas privadas.[...]"

Respecto al marco normativo, Argentina ratificó el Protocolo Adicional a la Convención Americana sobre Derechos Humanos en materia de Derechos Económicos, Sociales y Culturales "Protocolo de San Salvador", que en su artículo 11, titulado "Derecho a un Medio Ambiente Sano" dispone que: "1. Toda persona tiene derecho a vivir en un medio ambiente sano y a contar con servicios públicos básicos. 2. Los Estados partes promoverán la protección, preservación y mejoramiento del medio ambiente."

Particularmente, en cuanto a la relación entre los pueblos indígenas y el ambiente se ha reconocido el derecho tanto en normas del ámbito internacional como nacional. Por un lado tenemos normativas ambientales que hacen referencia a los pueblos indígenas. Aquí se destaca el Principio 22 de la Declaración de Río de Janeiro de 1992, que enfatiza el papel fundamental que tienen las poblaciones y comunidades indígenas en cuanto al cuidado del medio ambiente, debido a sus conocimientos y prácticas tradicionales. Y expresa que los Estados "deberían reconocer y apoyar debidamente su identidad, cultura e intereses y hacer posible su participación efectiva en el logro del desarrollo sostenible".

Otra normativa a destacar del ámbito internacional es el Convenio de Diversidad Biológica, también resultado de la Cumbre de Río del 92, ratificado por Argentina (Ley N²4.375), que en el artículo 8.j. respecto a la Conservación in situ de la biodiversidad, impone al Estado respetar, preservar y mantener los conocimientos, las innovaciones y las prácticas de las comunidades indígenas y locales que entrañen estilos tradicionales de vida pertinentes para la conservación y la utilización sostenible de la diversidad.

Específicamente a nivel nacional, se destaca la Ley de Presupuestos Mínimos de Protección Ambiental de los Bosques Nativos N²6.331, que en el Capítulo 7 "Audiencia y Consulta Pública", artículo 26, establece que la autoridad de aplicación debe tomar las 
medidas necesarias para garantizar el acceso a la información y la participación de los pueblos indígenas sobre las autorizaciones que se otorguen para desmontes.

Respecto a la legislación en materia indígena que hace referencia a lo ambiental, tenemos varios documentos internacionales de gran relevancia. En primer lugar el Convenio $N^{\circ} 169$ de la OIT que destaca esta relación principalmente en los artículos 4, 7 y 15. El artículo 4 establece que deberán adoptarse, en armonía con los deseos expresados por los pueblos interesados, todas las medidas necesarias para salvaguardar el medio ambiente. El artículo 7, se refiere al proceso de desarrollo y el derecho de los pueblos indígenas de decidir en base a sus propias prioridades para que no afecte sus vidas, creencias, bienestar espiritual y tierras que ocupan. Además, estos pueblos deben participar en la formulación, aplicación y evaluación de los planes y programas de desarrollo nacional y regional susceptibles de afectarles directamente. Y en el punto 3, especialmente determina "Los gobiernos deberán velar porque, siempre que haya lugar, se efectúen estudios, en cooperación con los pueblos interesados, a fin de evaluar la incidencia social, espiritual y cultural y sobre el medio ambiente que las actividades de desarrollo previstas puedan tener sobre esos pueblos. Los resultados de estos estudios deberán ser considerados como criterios fundamentales para la ejecución de las actividades mencionadas." Y el punto 4 establece: “Los gobiernos deberán tomar medidas, en cooperación con los pueblos interesados, para proteger y preservar el medio ambiente de los territorios que habitan."

Por último, el artículo 15 protege especialmente los derechos de los pueblos indígenas a los recursos naturales existentes en sus tierras. Expresa que las comunidades tienen derechos a participar en la utilización, la administración y la conservación de dichos recursos. En el punto 2 hace expresa referencia a los recursos naturales que pertenecen al Estado, y obliga a los gobiernos a garantizar procedimientos para la consulta a los pueblos interesados antes de autorizar cualquier programa de prospección o explotación de los recursos existentes en sus tierras, con el fin de determinar si los intereses de los pueblos indígenas serían afectados y en qué medida. Además de lo anterior, indica que los pueblos indígenas deberán participar en los beneficios que reporten esas actividades siempre que sea posible; y percibir una indemnización en caso de sufrir un daño como consecuencia de esas actividades.

También se destacan en este marco internacional las dos Declaraciones sobre los Derechos de los Pueblos Indígenas. Por un lado, la Declaración de las Naciones Unidas, en su artículo 29 determina que: “1. Los pueblos indígenas tienen derecho a la conservación y protección del medio ambiente y de la capacidad productiva de sus tierras o territorios y recursos. Los Estados deberán establecer y ejecutar programas de asistencia a los pueblos indígenas para asegurar esa conservación y protección, sin discriminación." Y luego vincula el derecho al ambiente y la salud de las comunidades originarias al referirse a los materiales peligrosos que puedan encontrarse en las tierras o territorios indígenas. También el artículo 32 de este documento se refiere a la protección del territorio y los recursos naturales, de la siguiente manera: "1. Los pueblos indígenas tienen derecho a determinar y elaborar las prioridades y estrategias para el desarrollo o la utilización de sus tierras o territorios y otros recursos. 2. Los Estados celebrarán consultas y cooperarán de buena fe con los pueblos indígenas interesados por conducto de sus propias instituciones representativas a fin de obtener su consentimiento libre e informado antes de aprobar cualquier proyecto que afecte a sus tierras o territorios y otros recursos, particularmente en relación con el desarrollo, la utilización o la explotación de recursos 
minerales, hídricos o de otro tipo. 3. Los Estados proveerán mecanismos eficaces para la reparación justa y equitativa por cualquiera de esas actividades, y se adoptarán medidas adecuadas para mitigar las consecuencias nocivas de orden ambiental, económico, social, cultural o espiritual."

Por otro lado, la Declaración Americana sobre los Derechos de los Pueblos Indígenas, establece en el artículo XIX específicamente el derecho a la protección del medio ambiente sano, y consideramos significativa su cita completa, porque introduce las ideas de vivir en armonía, de espiritualidad, cosmovisión y bienestar colectivo que son indispensables para la vida de los pueblos indígenas.

“1. Los pueblos indígenas tienen derecho a vivir en armonía con la naturaleza y a un ambiente sano, seguro y sustentable, condiciones esenciales para el pleno goce del derecho a la vida, a su espiritualidad, cosmovisión y al bienestar colectivo. 2. Los pueblos indígenas tienen derecho a conservar, restaurar y proteger el medio ambiente y al manejo sustentable de sus tierras, territorios y recursos. 3. Los pueblos indígenas tienen el derecho de ser protegidos contra la introducción, abandono, dispersión, tránsito, uso indiscriminado o depósito de cualquier material peligroso que pueda afectar negativamente a las comunidades, tierras, territorios y recursos indígenas 4. Los pueblos indígenas tienen derecho a la conservación y protección del medio ambiente y de la capacidad productiva de sus tierras o territorios y recursos. Los Estados deberán establecer y ejecutar programas de asistencia a los pueblos indígenas para asegurar esa conservación y protección, sin discriminación."

\section{IV.3.b. El derecho a la alimentación adecuada}

La Corte considera que este derecho "protege, esencialmente, el acceso de las personas a alimentos que permitan una nutrición adecuada y apta para la preservación de la salud". Luego cita lo señalado por el Comité de Derechos Económicos, Sociales y Culturales (Comité DESC) que expresa "el derecho se ejerce cuando las personas tienen acceso físico y económico, en todo momento, a la alimentación adecuada o a medios para obtenerla, sin que deba interpretarse [...] en forma estrecha o restrictiva asimilándolo a un conjunto de calorías, proteínas y otros elementos nutritivos concretos". En este concepto subyacen las ideas no sólo de seguridad, sino también de soberanía alimentaria.

Este derecho a la alimentación adecuada, a diferencia del anterior, no está receptado expresamente en un artículo de nuestra Constitución Nacional, pero si a través de diferentes instrumentos internacionales que tienen jerarquía constitucional conforme al artículo 75 inciso 22. Entre ellos, podemos destacar, siguiendo a la Corte, la Declaración Americana de Derechos y Deberes del Hombre que en el artículo XI dispone que "toda persona tiene derecho a que su salud sea preservada por medidas sanitarias y sociales, relativas a la alimentación". El artículo 12.1 del Protocolo de San Salvador, expresa que "toda persona tiene derecho a una nutrición adecuada que le asegure la posibilidad de gozar del más alto nivel de desarrollo físico, emocional e intelectual". La Declaración Universal de Derechos Humanos, en su artículo 25.1 prevé que: "toda persona tiene derecho a un nivel de vida adecuado que le asegure, así como a su familiar, la salud y el bienestar, y en especial la alimentación". En términos similares, el Pacto Internacional de Derechos Económicos, Sociales y culturales expresa que "los Estados Partes [...] reconocen el derecho de toda persona a un nivel de vida adecuado para sí y su familia, incluso alimentación" (artículo 11.1). 


\section{IV.3.c. El derecho al agua}

Respecto al contenido de este derecho, la Corte sigue lo expresado por el Comité DESC, al citar: "[...] el derecho humano al agua es el derecho de todos a disponer de agua suficiente, salubre, aceptable, accesible y asequible para el uso personal y doméstico. Un abastecimiento adecuado de agua salubre es necesario para evitar la muerte por deshidratación, para reducir el riesgo de las enfermedades relacionadas con el agua y para satisfacer las necesidades de consumo y cocina y las necesidades de higiene personal y doméstica".

La Corte, continua tomando las palabras del Comité DESC al decir que el derecho al agua comprende tanto libertades como derechos. Libertades en el sentido de no tener injerencias y mantener el acceso a un suministro de agua. Los derechos se vinculan a "un sistema de abastecimiento y gestión del agua que ofrezca a la población iguales oportunidades de disfrutar del derecho". Se destaca la concepción del agua como un bien social y cultural, dejando de lado la visión de un recurso natural como un bien económico propia de la racionalidad instrumental. En el mismo documento, el Comité DESC expresa que este derecho debe dar cumplimiento a tres factores: la disponibilidad, la calidad y la accesibilidad.

Respecto a las obligaciones que conlleva el derecho al agua, y que en este caso interesa especialmente al tratarse del Estado, la Corte ha indicado que implica tanto obligaciones de realización progresiva como inmediatas, y concuerda con el Comité DESC al señalar que se debe prestar especial atención a las personas y grupos vulnerables, que tradicionalmente han tenido dificultades para ejercer este derecho, entre ellos los pueblos indígenas.

Respecto al marco normativo, la Corte plantea lo mismo que en el derecho anterior. Nuestro país no reconoce de manera expresa en su Constitución el derecho al agua, pero lo hace a través de la jerarquía constitucional que le otorgó a los instrumentos de derechos humanos (artículo 75 inciso 22). Entre ellos, la Corte destaca que en los instrumentos generales no hay un reconocimiento expreso del derecho al agua, pero se lo entiende incluido al referirse, por ejemplo, el artículo 25 de la Declaración Universal de los Derechos Humanos al derecho a "un nivel de vida adecuado", al igual que el Pacto Internacional de Derechos Económicos, Sociales y Culturales en el artículo 11. Entre los que si hacen referencia expresa se encuentran tratados referidos a aspectos específicos de protección de los derechos humanos, como la Convención sobre los Derechos del Niño, en el artículo 24; o la Convención sobre la Eliminación de todas las Formas de Discriminación contra la Mujer en el artículo 14.

\section{IV.3.d. El derecho a participar en la vida cultural}

El derecho a participar en la vida cultural, incluye el derecho a la identidad cultural. En cuanto al concepto de cultura, la Corte cita lo señalado por la Organización de las Naciones Unidas para la Educación, la Ciencia y la Cultura (UNESCO), que la ha definido como "el conjunto de los rasgos distintivos espirituales y materiales, intelectuales y afectivos que caracterizan a una sociedad o a un grupo social y que abarca, además de las artes y las letras, los modos de vida, las maneras de vivir juntos, los sistemas de valores, las tradiciones y las creencias". Sostiene que la diversidad cultural debe ser protegida por los Estados, ya que, en palabras de la UNESCO: "constituye el patrimonio común de la humanidad y deber ser reconocida y consolidada en beneficio de las generaciones presentes y futuras". 
La Corte entiende que "el derecho a la identidad cultural tutela la libertad de las personas, inclusive actuando en forma asociada o comunitaria, a identificarse con una o varias sociedades, comunidades, o grupos sociales, a seguir una forma o estilo de vida vinculado a la cultura a la que pertenece y a participar en el desarrollo de la misma. En ese sentido, el derecho protege los rasgos distintivos que caracterizan a un grupo social, sin que ello implique negar el carácter histórico, dinámico y evolutivo de la cultura."

Respecto al marco normativo, la Constitución Nacional, estableció en el artículo 75 inciso 17 que "[...] corresponde al Congreso [...] reconocer la preexistencia étnica y cultural de los pueblos indígenas argentinos" y "[...] garantizar el respeto a su identidad"; esto implicó que Argentina comience a reconocerse como un Estado pluriétnico y a proteger la diversidad cultural existente en su interior. Además, como se resaltó en los demás derechos, a partir de la reforma de 1994 se otorgó a los tratados internacionales de derechos humanos jerarquía constitucional. Y aquí se destaca el artículo XIII de la Declaración Americana que indica "[...] toda persona tiene el derecho de participar en la vida cultural de la comunidad"; y el artículo 14.1 del Protocolo de San Salvador que reconoce "el derecho de toda persona a [...] participar en la vida cultural". En el ámbito universal, la Declaración Universal de los Derechos Humanos, en su artículo 27.1, dispone que: “[...] toda persona tiene derecho a tomar parte libremente en la vida cultural de la comunidad". El Pacto Internacional de Derechos Económicos, Sociales y Culturales en su artículo 15.1.a. señala "el derecho de toda persona a [...] participar en la vida cultural". Además, el Pacto Internacional de Derechos Civiles y Políticos prevé en su artículo 27 que "[...] en los Estados en que existan minorías étnicas, religiosas o lingüísticas, no se negará a las personas que pertenezcan a dichas minorías el derecho que les corresponde, en común con los demás miembros de su grupo, a tener su propia vida cultural, a profesar y practicar su propia religión y a emplear su propio idioma". Por último, el artículo 31 de la Declaración de las Naciones Unidas sobre los Derechos de los Pueblos Indígenas protege expresamente el patrimonio cultural.

\section{Los DESCA y los conflictos etnoambientales}

Como se expresó en la introducción, en los conflictos etnoambientales se entrelazan cuestiones indígenas y ambientales, por lo que requieren un enfoque especial. Han sido definidos como "[...] un tipo de disputa que tiene que ver con el tema ambiental, y en que influye la diversidad étnica de sus actores" (Lillo Vera, 2017: 28). En otras palabras, "se trata de conflictos en los que confluyen dos tipos de derechos, los ambientales y los indígenas, ambos con especial protección constitucional (arts. 41 y 75 inc. 17, CN) y estrechamente vinculados, tal como ha advertido la Corte Interamericana de Derechos Humanos en la Opinión Consultiva OC-23/17, en la que reconoce a las comunidades indígenas como grupos especialmente vulnerables a los daños ambientales" (Chiacchiera Castro, 2019: 1).

Las causas de su proliferación en las últimas décadas son diversas, siguiendo a Chiacchiera Castro (2019), distinguimos: económicas, culturales y jurídicas. Respecto a las causas económicas, la autora señala que hay coincidencia entre los territorios indígenas y la riqueza natural, lo que los convierte en un sector especialmente afectado por las disputas por el control de los recursos naturales, constituyendo los espacios "más rentables" para los inversionistas (Lillo Vera, 2017: 29). En cuanto a las causas culturales, destaca que hay cosmovisiones muy diferentes que subyacen en este tipo de conflictos que se muestran en la diferente concepción del medio ambiente entre la racionalidad antropocéntrica occidental y la visión cosmocéntrica indígena. Finalmente, entre las causas 
jurídicas, Chiacchiera Castro destaca el "reconocimiento de los pueblos indígenas como sujetos de derechos, con personalidad jurídica propia, que pueden reclamar sus derechos en clave colectiva, los que encuentran ahora sustento en normas constitucionales y convencionales" (2019: 2).

Siguiendo a Lillo Vera (2017) entre las características de los conflictos etnoambientales se destacan: 1) el escenario desigual en el que se desenvuelven, debido a la gran diferencia de poder entre las partes, donde generalmente, de un lado tenemos una empresa o al mismo gobierno con un proyecto económico de explotación de los recursos naturales, y por otro lado, tenemos a las comunidades locales, especialmente indígenas, muy vulnerables $^{9}$; 2) el constituir una lucha por el control y uso de los recursos naturales más que por la conservación ambiental en sí.

A partir de lo anterior, el autor especifica la definición de los conflictos etnoambientales como "aquellos que se dan entre el Estado y/o las empresas privadas con los pueblos indígenas, por el control de los recursos. Donde, la explotación irracional contenida en proyectos industriales planteados desde una perspectiva utilitarista, provoca no sólo el deterioro del medio ambiente (desde una perspectiva ecológica), sino también la calidad de vida de las poblaciones que habitan esos espacios, lo que constituye una vulneración de los derechos de los pueblos indígenas" (Lillo Vera, 2017: 30).

Como se expresó al hacer referencia al Acuerdo de Escazú, considerando estos conflictos particularmente en nuestra región, América Latina, cada vez es más grave la realidad de amenazas a los derechos y formas de vida de las comunidades indígenas. "Las decisiones y políticas relativas al uso y acceso a bienes ambientales, esenciales para la supervivencia física, cultural y espiritual de los pueblos indígenas, se encuentran en el centro de esta conflictividad" (Salles Cavedon Capdeville y Berros, 2020: 15). En otras palabras, "muchos de los ataques a personas defensoras de derechos humanos ambientales surgen en contextos de conflictos socioambientales por proyectos de desarrollo, sean privados o públicos, que buscan explotar y extraer los recursos naturales cerca de -o en- las tierras comunitarias y territorios de los pueblos y comunidades rurales o indígenas sin su consentimiento. [...]Esta situación genera conflictos y disputas por el territorio y los bienes naturales entre las comunidades que se sienten despojadas de su propiedad, territorio y patrimonio cultural y espiritual; las empresas que buscan el retorno económico de su inversión y detentan permisos y concesiones que permiten la realización de los megaproyectos, y las autoridades del Estado que, por un lado, otorgan esos permisos y, por el otro, tienen la obligación de respetar y garantizar los derechos humanos de la población que vive en esos territorios." (Leyva Hernández y Cerami, 2020: 264-265).

En este marco de los conflictos etnoambientales, la sentencia de la CIDH que comentamos, ha dado importantes avances respecto a los DESCA; ya que, si bien, tenían reconocimiento de manera indirecta o por conexidad (por su vínculo con determinados derechos civiles y políticos), en este caso el Tribunal reconoce que los DESCA son plena y directamente justiciables (Rossi, 2020), lo que permite conocer y delimitar las obligaciones de los Estados para garantizar estos derechos (Ronconi y Barraco, 2021).

9 Aquí cabe destacar que, en el caso analizado, no se trata de un gran proyecto extractivo o de inversión en el territorio indígena, sino que sus derechos se ven afectados de manera particular por la presencia de población criolla en esas tierras, quienes también se encuentran en una situación de vulnerabilidad, y es lo que hace el caso más complejo aún. 
Ronconi y Barraco (2021) destacan dos aportes de la sentencia que, a su entender, tienen una incidencia directa en la justiciabilidad y exigibilidad de los DESCA en la región: 1) La afirmación de la interdependencia, autonomía e indivisibilidad de los DESCA, y la consecuente determinación de reparaciones en materia de DESCA; 2 ) La obligación de garantía respecto a los DESCA.

1) Respecto al primer aporte, la Corte destaca la interdependencia entre el derecho a un medio ambiente sano, incluido en el artículo 26 de la CADH, y los demás derechos humanos. Recordemos que esto ya se había explicitado en la Opinión Consultiva 23/17, pero este es el primer caso donde lo aborda de manera contenciosa al derecho, y va más allá, al expresar la interdependencia entre los DESCA que analiza en la sentencia, y que hemos explicitado: derecho al medio ambiente, derecho a la alimentación, derecho al agua y derecho a la vida cultural. Que los DESCA sean interdependientes quiere decir que "la violación de uno puede llevar a la violación o vulneración de otro/s" (Ronconi y Barraco, 2021:...) y a su vez autónomos, significa que "su violación no puede depender de la violación de otro" (Ronconi y Barraco, 2021: ...). Esta concepción de interdependencia y autonomía entre los DESCA afectados ha implicado que se determinen medidas de reparación independientes, pero que a su vez impactan en los demás derechos.

La Corte, en la sentencia, dedica un título específico a la interdependencia entre los derechos a un ambiente sano, a la alimentación adecuada, al agua y a la identidad cultural; mostrando que "algunos aspectos que hacen a la observancia de uno de ellos pueden estar imbricados con la satisfacción de los otros". Resalta que el derecho a la alimentación, al agua y a participar en la vida cultural, resultan particularmente vulnerables a afectaciones ambientales. Luego, lo vincula específicamente con los pueblos indígenas, destacando el marco normativo: Convenio N¹69 de la OIT, Declaración de las Naciones Unidas sobre los Derechos de los Pueblos Indígenas y la Declaración Americana sobre Derechos de los Pueblos Indígenas. También destaca el Convenio sobre Diversidad Biológica y la Declaración de Río 92, a los que ya se ha hecho referencia.

En palabras de la Corte: “corresponde tener en consideración la interdependencia de los derechos analizados y la vinculación que presenta el goce de los mismos en las circunstancias del caso. Asimismo, tales derechos no deben ser entendidos en forma restrictiva. Ya se ha dicho [...] que el ambiente se encuentra relacionado con otros derechos, y que hay "amenazas ambientales" que pueden impactar en la alimentación, el agua y en la vida cultural. Por otra parte, no cualquier alimentación satisface el derecho respectivo, sino que la misma debe ser aceptable para una cultura determinada, lo que lleva a tener en cuenta valores no relacionados con la nutrición. La alimentación, a su vez, es indispensable para el goce de otros derechos, y su carácter "adecuado" puede depender de factores ambientales y culturales. La alimentación es, en sí, una expresión cultural. En ese sentido, puede considerarse a la alimentación como uno de los "rasgos distintivos" que caracterizan a un grupo social, quedando comprendido, por ende, en la protección del derecho a la identidad cultural a través de la salvaguarda de tales rasgos, sin que ello implique negar el carácter histórico, dinámico y evolutivo de la cultura. [...] Lo expresado es, a su vez, más evidente respecto de pueblos indígenas, en relación a los que normas específicas mandan la salvaguarda de su ambiente, la protección de la capacidad productiva de sus tierras y recursos, y a considerar como "factores importantes del mantenimiento de su cultura" actividades tradicionales y relacionadas con su economía de subsistencia, como caza, recolección y otras [...]". Una consideración relevante que hace la Corte es 
que debe entenderse, "al menos en términos apriorísticos", que el manejo por parte de las comunidades indígenas de los recursos existentes en sus territorios es favorable a la preservación del ambiente.

Teniendo presente que el eje de la revista es el derecho a la salud, en esta interrelación, no se puede dejar de hacer referencia a una nota al pie de la sentencia, en donde la Corte deja sentado que el derecho a la salud se incluye en el artículo 26 de la Convención, y que la relación entre alimentación, salud (a lo que se agregaría ambiente) resulta evidente. Luego, recuerda lo expresado en la Opinión Consultiva 23/17 donde indicó que entre las condiciones necesarias para una vida digna se encuentran el acceso y calidad del agua, alimentación y salud. Ha advertido que "entre dichas condiciones cabe destacar que la salud requiere de ciertas precondiciones necesarias para una vida saludable, por lo que se relaciona directamente con el acceso a la alimentación y al agua", y que "la contaminación ambiental puede causar afectaciones a la salud", por lo que la protección del ambiente se relaciona directamente con el acceso a la alimentación, al agua y a salud. En el mismo documento, la Corte ha expresado que el derecho al agua está "entre los derechos particularmente vulnerables a afectaciones ambientales". La Corte también cita la explicación del Comité DESC sobre el vínculo del derecho al agua con los demás derechos, donde señala la importancia de "garantizar un acceso sostenible a los recursos hídricos con fines agrícolas para el ejercicio del derecho a una alimentación adecuada". Luego, expuso que "los Estados [...] deberían garantizar un acceso suficiente al agua para la agricultura de subsistencia y para asegurar la de subsistencia de los pueblos indígenas". Sostuvo que "la higiene ambiental, como aspecto del derecho a la salud [...] entraña la adopción de medidas no discriminatorias para evitar los riesgos para la salud que representa el agua insalubre y contaminada por sustancias tóxicas".

2) En cuanto al segundo aporte, la Corte remarca de manera explícita la obligación de garantía que existe respecto de los DESCA, lo que constituyó un elemento clave para determinar la responsabilidad del Estado, "ya que lo que la Corte determinó fue, justamente, la falta de medidas eficaces por parte de Argentina para impedir que los criollos interfieran en el disfrute de los DESCA por parte de las comunidades indígenas. Esto implica, indudablemente, un avance concreto para los DESCA en el contexto latinoamericano. [...] Los Estados no solo deben adoptar políticas para dar debido cumplimiento a los DESCA, sino también garantizar su no vulneración por parte de terceros. Esto puede tener un impacto muy grande en la región en lo que se refiere al derecho a la salud, a la educación y a la vivienda, donde muchas veces los particulares tienen un rol central en su gestión." (Ronconi y Barraco, 2021: 16-17).

\section{Consideraciones finales}

Como corolario del recorrido realizado, se puede destacar que la Sentencia de la CIDH en el caso "Lhaka Honhat (Nuestra Tierra) vs. Argentina" constituye un precedente clave en la protección de los DESCA en general, y de los pueblos indígenas en particular. En este caso, además de pronunciarse sobre los derechos civiles y políticos, ampliando la interpretación del artículo 21 de la CADH sobre el derecho a la propiedad comunitaria de los pueblos originarios; se pronunció respecto a la justiciabilidad directa de los DESCA incluidos en el artículo 26 de la CADH, particularmente: el derecho al medio ambiente sano, a una alimentación adecuada, al agua y a participar en la vida cultural. En otras palabras, esta sentencia es de suma relevancia porque es la primera contra el Estado Argentino vinculado a los derechos de los pueblos indígenas, y además, es la primera vez que en un 
caso contencioso la Corte analiza esos derechos de forma interdependiente y autónoma, a partir del artículo 26 de la CADH, ordenando diferentes medidas de reparación que debe cumplir Argentina, y que supervisará para su cumplimiento efectivo.

Se recuerda que el litigio tiene como reclamo principal la propiedad comunitaria de las tierras que habitan 132 comunidades indígenas; y a partir de allí, la Corte en la sentencia, con una mirada integral, ubica este derecho a la propiedad comunitaria indígena como eje y condición necesaria para el goce de los demás DESCA analizados. Esto es de una importancia fundamental por el vínculo estrecho que tienen los pueblos indígenas con su territorio y los bienes comunes que allí se encuentran. Se trata de un vínculo con la Pachamama desde una cosmovisión totalmente diferente al uso que hacen las comunidades criollas que conviven en el mismo territorio; y por ello el problema central es esta convivencia y la afectación de los demás derechos que acarrea ese aprovechamiento de los recursos naturales. Precisamente, la complejidad especial del caso se encuentra en que no se trata de grandes y poderosos intereses privados, de inversión y explotación de los recursos naturales, sino de población criolla, campesina, que también se encuentra en situación de vulnerabilidad.

En ese marco, cabe recordar que la misma Corte destaca el indispensable rol de las comunidades indígenas para la protección del ambiente, por ello, es imprescindible garantizar su participación respecto a la gestión de los bienes naturales comunes. Tanto las decisiones judiciales (y administrativas), como la formulación e implementación de políticas públicas deben respetar la cosmovisión de estos pueblos; descolonizando las prácticas arraigadas.

Estos antecedentes internacionales, particularmente las sentencias de la $\mathrm{CIDH}$, son de gran importancia ante la insuficiencia del ordenamiento jurídico nacional; ya que si bien contamos con normas, no hay un cumplimiento efectivo, lo que continua afectando los derechos de las comunidades indígenas en nuestro país y América Latina en general. Por esto, la sentencia constituye un verdadero avance jurisprudencial para que estos derechos se garanticen por el Estado. 


\section{REFERENCIAS BIBLIOGRÁFICAS}

- Chiacchiera Castro, P. (2019). Conflictos etnoambientales, pueblos indígenas y Poder Judicial. Revista El Derecho. Diario de Doctrina y Jurisprudencia, UCA, N¹4.734, 1-4.

- Corte Interamericana de Derechos Humanos (2017). Opinión consultiva: Medio ambiente y Derechos Humanos (OC-23/17). Disponible en: http://www.corteidh.or.cr/docs/opiniones/seriea_23_esp.pdf.

- Corte Interamericana de Derechos Humanos (2020). Sentencia "Caso Comunidades Indígenas Miembros de la Asociación Lhaka Honhat (Nuestra Tierra) vs. Argentina". Disponible en: https://www.corteidh.or.cr/docs/casos/articulos/seriec_400_esp.pdf

- Fundación Ambiente y Recursos Naturales (FARN) (2019), Amicus Curiae Caso: Comunidades Indígenas Miembros de la Asociación Lhaka Honhat (Nuestra Tierra) vs. Argentina. Disponible en: https://farn.org.ar/wp-content/uploads/2020/06/FARN-Amicus-Curiae-deLhaka-Honhat.pdf

- Hualpa, E. (2020). Los pueblos indígenas en Argentina y el Acuerdo de Escazú. Revista Pulso Ambiental, No14, 17-19. Disponible en: https://farn.org.ar/wp-content/ uploads/2020/09/PulsoAmbiental-N\%C2\%BA14-Septiembre-2020.pdf

- Leyva Hernández A. y Cerami, A. (2020). El Acuerdo de Escazú ante la situación de riesgo de las personas defensoras ambientales en América Latina y el Caribe. En Prieur M., Sozzo, G. y Nápoli, A. (Ed.) Acuerdo de Escazú. Hacia la democracia ambiental en América Latina y el Caribe (pp.626-270). Disponible en: https://bibliotecavirtual. unl.edu.ar:8443/bitstream/handle/11185/5688/1-Libro\%20ESCAZU\%CC\%81_Digital_ BV.pdf?sequence $=1$ \&isAllowed $=y$

- Lillo Vera, R. (2017). Conflictos ambientales en territorios indígenas. Disponible en: http://www.estudiosindigenas.cl/trabajados/lillo.pdf.

- Moreira, M. (2011). El Derecho de los Pueblos Indígenas, los cambios constitucionales y la interpretación judicial en la Argentina. Revista Argentina de Teoría Jurídica, V.12. Disponible en: https://repositorio.utdt.edu/handle/utdt/10686

- Ronconi L. y Barraco M. (2021). La consolidación de los DESCA en la Corte Interamericana de Derechos Humanos: reflexiones a propósito del caso Lhaka Honhat vs. Argentina. Revista de la Facultad de Derecho, №50. Disponible en: https://revista.fder.edu.uy/index. $\mathrm{php} / \mathrm{rfd} /$ article/view/773/1389

- Rossi, J. (2020). Punto de inflexión en la jurisprudencia de la Corte Interamericana de Derechos Humanos sobre DESCA. El camino de la justiciabilidad directa: de "Lagos del Campo" a "Asociación Lhaka Honhat". Revista Pensar en Derecho, Nº16, 183-235. Disponible en: http://www.derecho.uba.ar/publicaciones/pensar-en-derecho/revistas/16/ punto-de-inflexion-en-la-jurisprudencia-de-la-cidh-sobre-desca.pdf

- Salles Cavedon Capdeville F. y Berros M. (2020). Introducción. En Prieur M., Sozzo, G. y Nápoli, A. (Ed.) Acuerdo de Escazú. Hacia la democracia ambiental en América Latina y el Caribe (pp.14-18). Disponible en: https://bibliotecavirtual.unl. edu.ar:8443/bitstream/handle/11185/5688/1-Libro\%20ESCAZU\%CC\%81_Digital_ BV.pdf?sequence $=1$ \&isAllowed=y 